\title{
SURVIVAL ANALYSIS OF JOINT REPLACEMENTS
}

\author{
D. W. MURRAY, A. J. CARR, C. BULSTRODE
}

From the Nuffield Orthopaedic Centre, Oxford, England

\begin{abstract}
Survival analysis is a powerful tool for analysing the results of total joint replacement, but it has major drawbacks when the failure rates are very low. We have reviewed 35 recent survival analyses of joint replacements to assess the magnitude of these problems and make recommendations as to how they may be avoided.
\end{abstract}

J Bone Joint Surg [ Br] 1993; 75-B :697-704.

Received 3 August 1992; Accepted after revision 8 January 1993

The longevity of total joint replacements is an important measure of success which allows different designs to be compared. Survival or, as it is sometimes called, survivorship analysis is a powerful tool in this type of study, particularly when failure rates are high (Dobbs 1980), but there are inherent pitfalls when this type of analysis is used for joint replacements which have very low failure rates (less than $1 \%$ per year). We have tried to identify these problems, assess their importance and suggest how they may be avoided.

\section{MATERIALS}

We reviewed 35 survival analyses of total hip and total knee replacements published in major orthopaedic journals in the last six years, to obtain the information on which this paper is based. They are listed in Appendix 1.

One of these analyses was selected for detailed consideration and used as an example to demonstrate the problems, since it reported a very low failure rate. The survival rate of $98 \%$ at ten years (Fig. 1), taken at face value, could lead to the conclusion that the joint replacement studied should be used instead of others in current use. The demonstration analysis was also the only one which provided complete data, including information about when patients were lost to follow-up, and was therefore the only one suitable for a thorough critical review.

D. W. Murray, MD, FRCS, Senior Orthopaedic Registrar A. J. Carr, MD, FRCS, Consultant Orthopaedic Surgeon C. Bulstrode, MD, FRCS, Reader and Honorary Consultant Orthopaedic Surgeon

Nuffield Orthopaedic Centre NHS Trust, Windmill Road, Headington, Oxford OX3 7LD, UK.

Correspondence should be sent to Mr D. W. Murray.

(C) 1993 British Editorial Society of Bone and Joint Surgery

$0301-620 \mathrm{X} / 93 / 5597 \$ 2.00$

\section{SURVIVAL ANALYSIS}

Survival analysis is a method of analysing data from patients with different lengths of follow-up, allowing cases to enter and be withdrawn from a trial at any stage and for whatever reason. For the analysis it is assumed that all patients had their operation simultaneously. The chance of the implant surviving for a particular length of time, the survival rate, is then calculated. The calculations may be done either with a life table or by the productlimit method (Armitage and Berry 1987). Two-thirds of the 35 papers reviewed used a life table, and one-third the product-limit method. Survival curves can then show graphically how the survival rate changes with time (Fig. 1).

To construct a life table the number of joints being followed and the number of failures are determined for each year after operation (Table I: Dobbs 1980; Tew, Waugh and Forster 1985). The first year starts with the total number in the study. In subsequent years this number falls away gradually to zero. For each year of follow-up, the failure rate is calculated from the number of failures and the 'number at risk' (Appendix 2). The annual success rate, determined from the failure rate, is cumulated to give a survival rate for each successive year. This can therefore change only once a year. By contrast, the product-limit method recalculates the survival rate each time a failure occurs (Kaplan and Meier 1958).

There are advantages and disadvantages of both methods. With the product-limit method, because of the frequent recalculations, a table cannot be constructed.

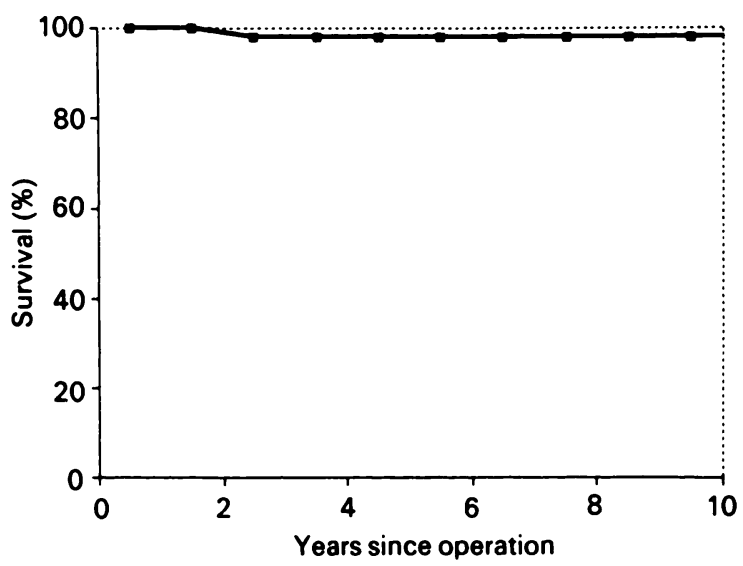

Fig. 1

Ten-year survival curve for the demonstration analysis. 
Table I. Life table for the demonstration data. This includes a column for patients lost to follow-up

\begin{tabular}{lllllllll}
\hline $\begin{array}{l}\text { Years since } \\
\text { operation }\end{array}$ & $\begin{array}{l}\text { Number } \\
\text { at start }\end{array}$ & Failure & Withdrawn & $\begin{array}{l}\text { Lost to } \\
\text { follow-up }\end{array}$ & $\begin{array}{l}\text { Number } \\
\text { at risk }\end{array}$ & $\begin{array}{l}\text { Annual } \\
\text { failure rate } \\
\text { (per cent) }\end{array}$ & $\begin{array}{l}\text { Annual } \\
\text { success rate } \\
\text { (per cent) }\end{array}$ & $\begin{array}{l}\text { Survival rate } \\
\text { (per cent) }\end{array}$ \\
\hline 0 to 1 & 67 & 0 & 7 & 6 & 63.5 & 0.0 & 100.0 & 100 \\
1 to 2 & 60 & 0 & 4 & 3 & 58.0 & 0.0 & 100.0 & 100 \\
2 to 3 & 56 & 1 & 6 & 4 & 53.0 & 1.9 & 98.1 & 98 \\
3 to 4 & 49 & 0 & 5 & 0 & 46.5 & 0.0 & 100.0 & 98 \\
4 to 5 & 44 & 0 & 10 & 5 & 39.0 & 0.0 & 100.0 & 98 \\
5 to 6 & 34 & 0 & 7 & 5 & 30.5 & 0.0 & 100.0 & 98 \\
6 to 7 & 27 & 0 & 9 & 1 & 22.5 & 0.0 & 100.0 & 98 \\
7 to 8 & 18 & 0 & 3 & 0 & 16.5 & 0.0 & 100.0 & 98 \\
8 to 9 & 15 & 0 & 3 & 1 & 13.5 & 0.0 & 100.0 & 98 \\
9 to 10 & 12 & 0 & 6 & 0 & 9.0 & 0.0 & 100.0 & 98 \\
10 to 11 & 6 & 0 & 3 & 1 & 4.5 & 0.0 & 100.0 & 98 \\
11 to 12 & 3 & 1 & 2 & 0 & 2.0 & 50.0 & 50.0 & 49 \\
\hline
\end{tabular}

Such a table is advantageous because it can include details of the number of joints followed, the number of failures and the number lost to follow-up. The life-table method also allows confidence limits to be determined and displayed more readily. The theoretical advantages of the product-limit method are that the arbitrary choice of time intervals is avoided, and that it is more accurate, since the survival rate can change during the intervals. For joint replacements, however, these advantages are negligible because patients are commonly reviewed annually. We therefore recommend the use of the lifetable method with presentation of both the survival curve and the life table.

The tail of the survival curve. Towards the end of followup there may be very few patients remaining in the study and the failure of only one case can dramatically reduce the survival rate. The tail of the survival curve is therefore likely to be unreliable. Differences between implants, however, may become apparent only at long-term followup, and therefore authors who do not present the last few years of their survival curves, because of their unreliability, may exclude important information. This is well shown by the demonstration analysis: the survival curve for the first ten years of the trial gives a very different impression from the complete survival curve (Figs 1 and 2).

There is good reason to believe that survival curves of joint replacements are not linear, as the failure rate follows the U-shaped curve of all mechanical devices. A high initial failure rate, as a result of faulty manufacture or faulty fitting is followed by a period when failure is rare. Towards the end of design life the incidence of failure rises as components wear out. It should therefore be mandatory to present the whole of a survival curve, with confidence limits to show the reliance that can be put on the tail.

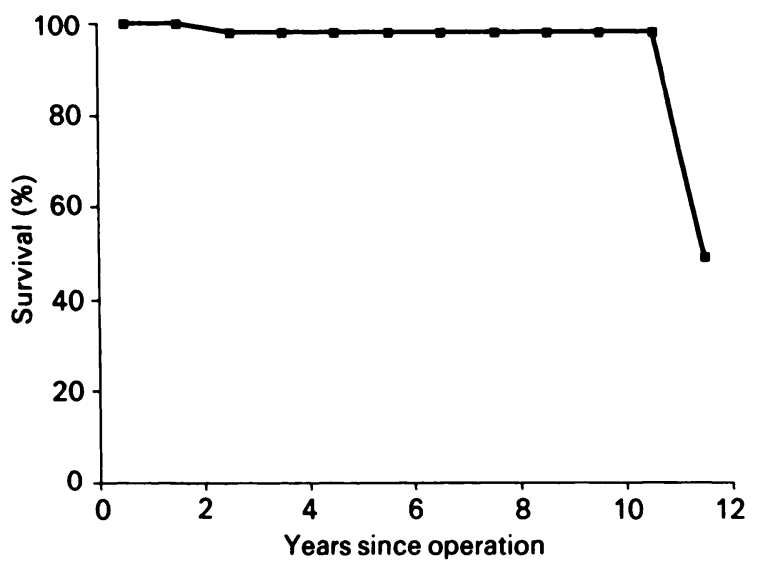

Fig. 2

The complete survival curve for the demonstration analysis.

Small numbers. The number of joints remaining in the follow-up is an important variable determining the reliability of the data. Half of the papers that we studied did not give the numbers being followed each year, and in those that did, half had numbers of less than ten in the year for which the survival rate was quoted in the abstract. With numbers as low as ten the possible error is of the order of $20 \%$, which was often larger than the cumulative failure rate (Peto 1984).

The number at risk should always be presented either in the life table or on the survival curve, so that even a statistically inexperienced reader can gain an impression of the reliability of the survival curve.

Confidence intervals. A number of authors have advised that $95 \%$ confidence limits should be plotted in order to demonstrate the reliability of a survival curve (Lettin, Ware and Morris 1991; Nelissen, Brand and Rozing 1992). Only $20 \%$ of the papers that we reviewed included 

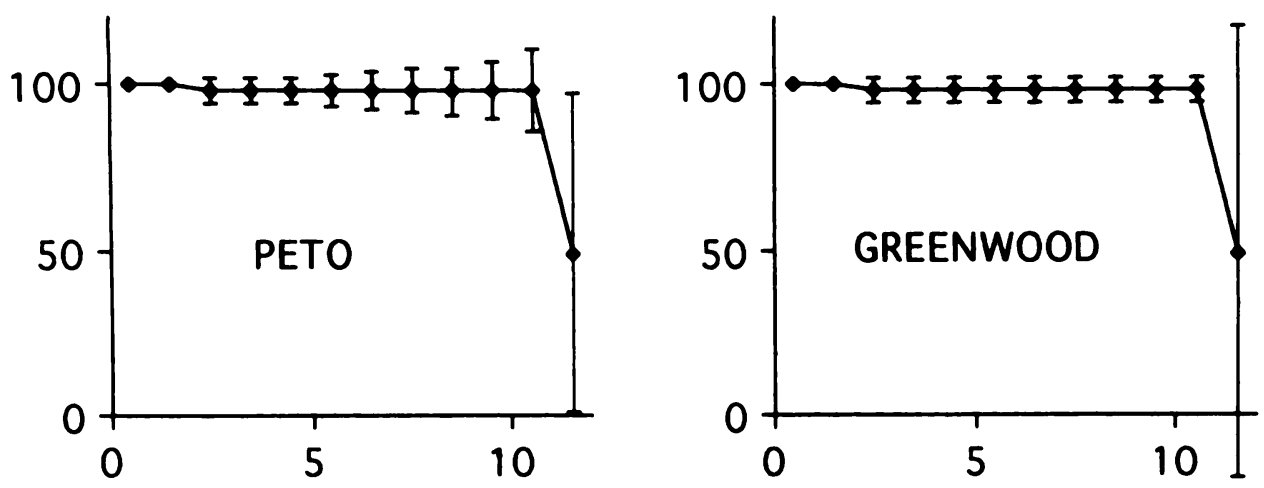

Fig. 3
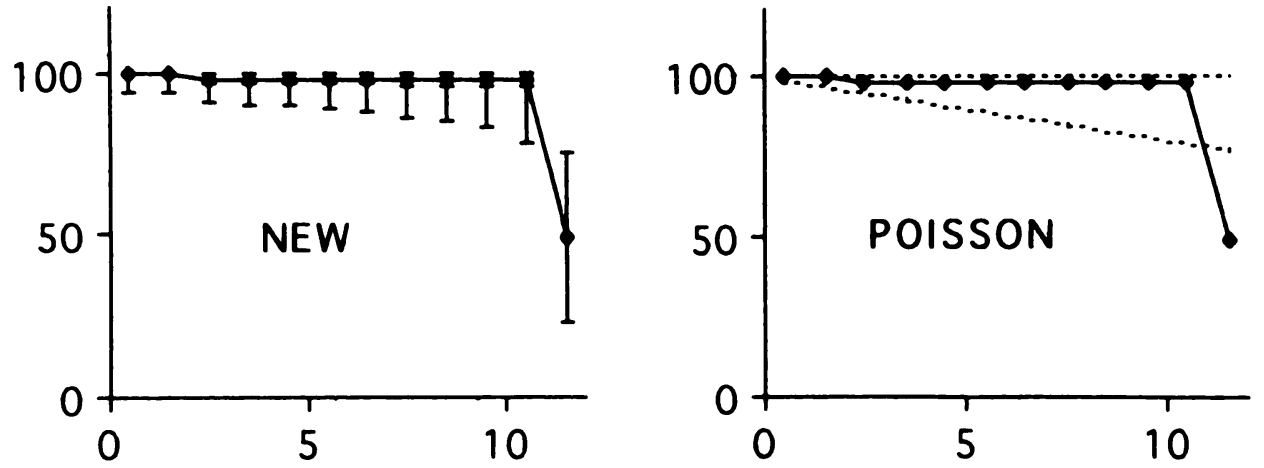

Four different methods of calculating $95 \%$ confidence limits for the demonstration data. With the NEW method the confidence limits were determined from the 'effective number at risk' using Rothman's equation (Appendices 5 and 6).

such confidence limits, and only $25 \%$ of these gave the method by which the limits were calculated. The methods of Greenwood (1926) or Peto et al (1977) are usually used. Although both are satisfactory with moderate failure rates, neither is acceptable with very low failure rates. In these situations statistical techniques appropriate to rare events, such as the Poisson distribution, should ideally be used. These techniques are, however, not appropriate if the failure rate is not constant.

Confidence limits are determined from an equation linking the number of joints and the survival rate. The Greenwood equation calculates the confidence limits in any given year from the number at risk during the years in which there were failures (Appendix 5) and is therefore biased towards the early years when the number of patients are higher. This is shown by the demonstration analysis (Fig. 3). In year 10 there were only nine patients remaining in the study; there had previously been only one failure, which occurred in year 3 when there were 53 patients in the study. The Greenwood equation calculates confidence limits as if 53 patients had been followed for ten years, thereby grossly underestimating the confidence intervals.

The Peto equation (Appendix 4) calculates the confidence limits for the year in question in isolation, taking little account of the fact that many more patients may have been followed in earlier years. Because of this the confidence intervals tend to be overestimated.
For the demonstration data the Peto equation calculates the confidence limits as if there were only nine patients and they had all been followed for ten years. There is another problem with the Peto equation: the one that is used (the binomial variance equation, Appendix 3) is not appropriate for very low failure rates. In these situations it tends to underestimate the lower confidence limits and overestimate the upper confidence limit. The Peto equation may therefore over- or underestimate the confidence limits depending on the failure rate. In the demonstration analysis the lower limit is underestimated, and the upper limit is overestimated and is greater than $100 \%$ (Fig. 3).

Ideally, confidence limits should be derived predominantly from the year in question, but should also include information from earlier years. One way of achieving this is to base the confidence limits on the 'effective number at risk' (Cutler and Ederer 1958). We have developed a new method of determining the effective number at risk (Appendix 5), which can best be appreciated by considering the accuracy of the survival rate, as assessed by the variance. The accuracy is inversely proportional to the number at risk. The average accuracy, which is inversely proportional to the effective number at risk, is equal to the average of the accuracies in each year. Thus the effective number at risk is equal to the harmonic mean of the numbers at risk in each year.

For the demonstration data the effective number at 
risk at ten years is 24 . With low failure rates the confidence limits should be obtained from the effective number at risk using an exact method (unless very large numbers are involved, in which case the binomial variance equation may be used, Appendix 3). Of the possible exact methods, which include calculations, tables or use of the $\mathrm{F}$ distribution, we have used the method of Rothman (1978, Appendix 6) (Armitage and Berry 1987). Confidence limits for the example data have been obtained using Rothman's equation and the effective number at risk (Fig. 3). This method, which is not difficult to apply with a personal computer, generates confidence limits that do not cross the boundaries of the graph, that are asymmetrical, and are likely to be reliable.

The Poisson distribution may be used if it can be assumed that within a trial the failure rate remains reasonably constant, and is low. This assumption is not usually valid because of the U-shape of the typical failure curve. To use the Poisson distribution it is necessary to determine the number of failures during the trial (two in the demonstration data) and the total number of years in which joints were at risk ( 358 in the demonstration data). This is determined by adding together the number of patients at risk for each year. The confidence limits are then obtained from tables, such as Table $\mathbf{4 0}$ of Pearson and Hartley (1966). In the example the $95 \%$ confidence limits are 0.2 and 7.2 failures. The expected annual failure rate is $0.6 \%(2 / 358 \times 100 \%)$ with confidence limits $2 \%$ and $0.07 \%(7.2 / 358 \times 100 \%$ and $0.2 / 358 \times 100 \%)$. The expected 10-year survival rate is therefore $94 \%$, with confidence limits of $80 \%$ and $99 \%$. The confidence limits determined from the Poisson distribution are different from the others in that they are determined once for the complete trial and not annually. They should therefore be plotted as straight lines (Fig. 3).

It is essential that confidence limits are plotted on survival curves, and given whenever survival rates are quoted. We recommend that they be based on the 'effective number at risk', which is the harmonic mean of the number at risk in the year in question and preceding years (Appendix 5). They should ideally be determined by an exact method if the failure rate is low, or by an approximate method if the rate is high or the number at risk is high (binomial variance equation, Appendix 3). In the unlikely event that the failure rate can be assumed to be constant, and that there are very few failures, then the Poisson distribution may be used.

Loss to follow-up. A fundamental assumption in survival analysis is that patients who are lost to follow-up and patients who die have the same failure rate as those who complete the trial. This may be valid for those who die, but is unlikely to be true for those lost to follow-up (Sims 1973; Austin et al 1979) since implant failure may cause a patient to go elsewhere to seek 'better' treatment. Dorey and Amstutz (1989) carried out two studies on the same implant. In one study $45 \%$ were lost to follow-up and in the other $10 \%$ were lost. The survival rates were the same in both studies and they therefore concluded that loss to follow-up was not important. This conclusion has been challenged on the grounds that those patients unwilling to return for follow-up will be included in the last $10 \%$ which were lost from both studies (Laupacis 1989). When the failure rate is very low, even a single failure hidden within the patients who are lost to follow-up will have a profound effect on results.

The time interval for assessments has to be selected before a survival analysis is done; this interval is usually one year. Any patient not reviewed during the last time interval of the trial, or after the trial has finished, is lost to follow-up, unless he or she has died. This definition must be rigidly applied to all survival analyses so that all patients lost to follow-up can be identified.

Only half of the 35 papers reviewed gave figures on the numbers lost to follow-up, and in most of these this loss was about $5 \%$ (median $6 \%$, interquartile range $4 \%$ to $10 \%$ ). It is likely that in the other papers the loss to follow-up was even higher. Only one paper reported the year in which the losses occurred. Unless this information is available the effect of loss to follow-up cannot be determined. We therefore recommend that a column for patients lost to follow-up be included in the life table.

To give an impression of the effect of loss to followup it is possible to plot a worst-case curve, based on the assumption that all patients lost to follow-up have failed (Fig. 4). The reader can then be certain that the true survival curve lies somewhere between this and the standard survival curve. If the rate of loss to follow-up is high the worst-case curve degrades the results so dramatically that it would provide a powerful incentive to all authors to avoid loss to follow-up. As it is unlikely that all patients lost to follow-up are failures, an alternative to a worst-case curve would be a loss-tofollow-up curve based on the assumption that the failure rate of those lost was some arbitrary multiple of those not lost to follow-up. This would give a more precise impression of the effect of loss to follow-up, but it would be difficult to reach a consensus as to what the arbitrary function should be. A worst-case curve is therefore more practical.

Definition of failure. Any definition of failure may be used for survival analysis. Many different definitions have been used, and, not surprisingly, they generate different survival rates (Nelissen et al 1992). Revision of an arthroplasty is the most widely used definition: it is simple to identify and reproducible $(70 \%$ of the analyses reviewed used revision). There are, however, significant problems with its use : revision rates may be very low and the timing of revision is influenced by many extraneous factors. Revision may be delayed or even postponed indefinitely if the service lacks resources, or the patient is too ill for surgery. In such cases early failures will be classified as continuing successes. There is no simple solution, but one option is to make separate analyses for different definitions of failure, some of which have a 


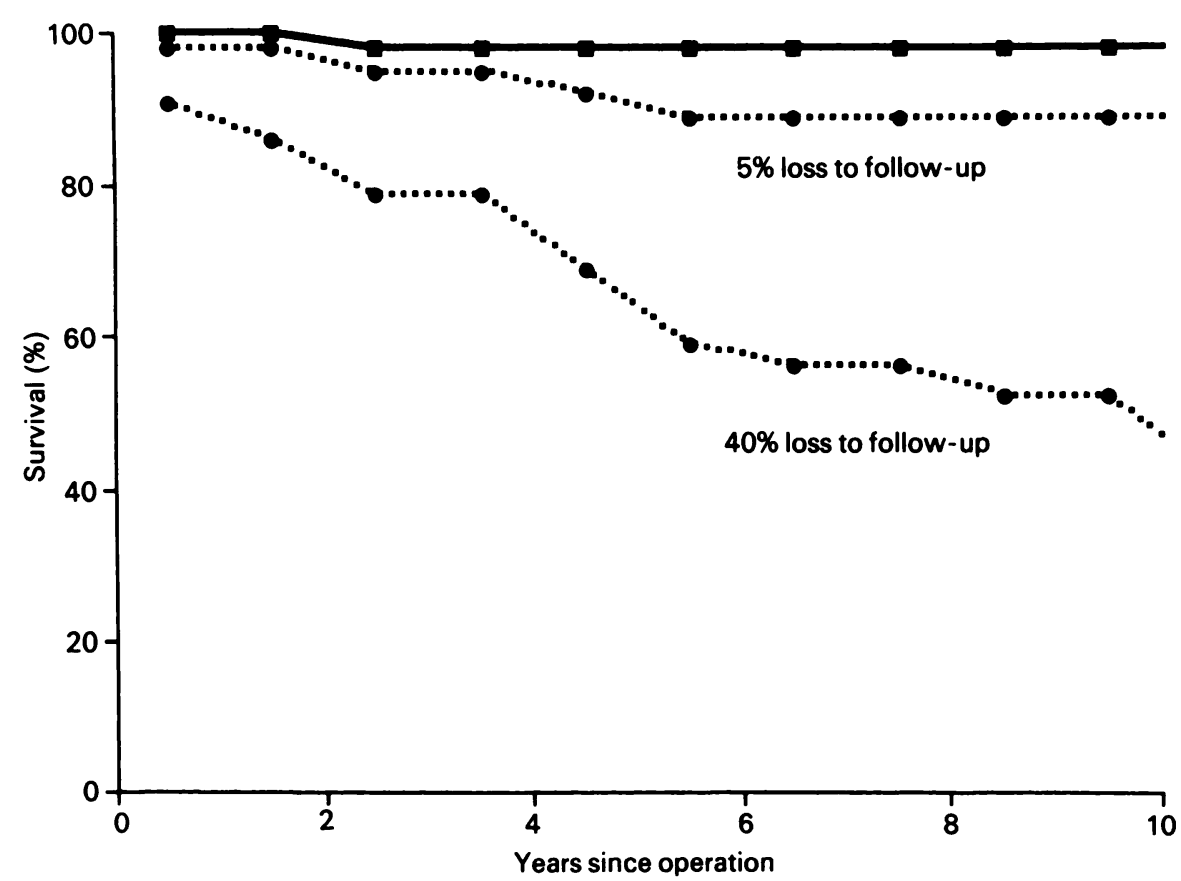

Fig. 4

Worst-case curves for the demonstration analysis prepared by assuming that joints lost to follow-up were failures. Two curves are plotted, one assuming that $5 \%$ and the other that $40 \%$ of the joints were lost to follow-up. The actual proportion lost to follow-up in the demonstration paper was $40 \%$.

reasonably high chance of occurring. These definitions should ideally include an outcome measure which could be considered to be a total failure, one which could be considered to be a partial failure, and one which is an early predictor of failure.

Several authors have used outcome measures other than revision which could be considered to indicate total failure. These include severe pain, a high pain score, a low Harris hip score, and the recommendation for revision. The primary indication for joint replacement is usually pain, and therefore one outcome measure that should be considered as total failure is the development of severe pain or pain as bad as before the original operation, taking severe pain as grade 1 or 2 on the scales of Merle d'Aubigné and Postel (1954) or Charnley (1972). Many outcome measures with a moderate chance of occurring have been used; these include the development of radiolucent lines, subsidence, and moderate or mild pain. We suggest that the development of mild pain (grade 4 or less) should indicate partial failure of an implant. As yet there is no good early indicator of loosening. Until this is available the development of a wide radiolucent line with or without subsidence could be used as an outcome measure. None of these measures are reliable in isolation. Used together, however, they should be a useful method of assessing joint replacements. It will remain difficult to compare survival analyses until a consensus is reached about the outcome measures which should be assessed.

Long-term prediction. Survival analysis should not be used to extrapolate beyond the end of a study, although this was done in one of the papers reviewed. This is because the failure rate tends to increase with time: Ritter and Campbell (1987), analysing Charnley hip replacements, found that the failure rate remained constant at about $1 \%$ per year for the first ten years, but then increased to about $5 \%$ per year. Had the analysis stopped at ten years, a prediction based on the ten-year cumulative survival rate of $92 \%$ would forecast that the 15-year survival would be $88 \%$. In fact the 15 -year survival was about $65 \%$. To give another example, Ritter et al (1990) compared metal-backed with polyethylene sockets. The five-year survival rate for both was $98 \%$, and it could have been predicted that the long-term survival rate would be the same for both sockets. By seven years the survival rate for the metal-backed socket was $55 \%$, very much worse than the survival rate for allpolyethylene sockets, which remained at $98 \%$.

Bias towards good results. Large numbers of different joint replacements are being used world-wide; many of them are likely to be the subject of clinical trials assessed by survival analysis. Because of the laws of chance, about $1 \%$ of these trials will have outstandingly good results and will therefore be published. These joint replacements will therefore appear to be, and will be 'statistically proven' to be, better than others in current use, when in fact they are not. Furthermore, the time period that is selected for a clinical trial is likely to be that in which good results are obtained from the implant. These good results may be just a statistical aberration, causing the survival analysis to generate unrealistically good results.

Publication. When a survival analysis is carried out on a new implant, one of three conclusions may be drawn: the new implant may either be worse, as good as, or better 
than standard implants. Standard implants currently have a failure rate of about $1 \%$ per year. To justify the conclusion that an implant is worse than standard implants only a small number of patients with a relatively short follow-up are needed: if the failure rate is $5 \%$ per year, the difference will be clear if 50 patients are followed for three years, or 20 for four years. Data from such trials should be published as soon as they are available; three of the 35 papers that we reviewed were of this type.

If the conclusion is to be that an implant is as good as current implants, with a failure rate of about $1 \%$ per year, then ideally it will be necessary to follow a moderate number of patients for ten years. If the conclusion is to be that an implant is better than current implants, then survival analysis, using revision as the criterion for failure, may not be powerful enough to achieve this. Even if a perfect implant was produced and put in perfectly, it would require at least 10 to 15 years and thousands of patients (none lost to follow-up) before it could be shown to be statistically better than some of the currently published results. By this stage the implant design would have changed, and the survival rate of the implant being studied would be irrelevant. If more than one criteria for failure were used, survival analysis would be better able to distinguish between modern joint replacements. Until all studies analyse a number of different and standardised outcome measures comparison between different centres will be difficult. Ideally, properly designed randomised trials would be used to compare implants.

\section{Conclusions}

1) The life-table method of calculation should be used for survival analysis of joint replacements. A complete life table and a survival curve should be presented.

2) Life tables should include a column with the number of patients lost to follow-up. A worst-case survival curve should be plotted. This is derived by assuming that all cases lost to follow-up have failed.

3) Life tables and survival curves should include the number of patients at risk in any year. Confidence limits should be plotted on the curves and be quoted whenever survival data are given; they should usually be determined from the 'effective number at risk' using the new method described in this paper.

4) Extrapolated predictions of the survival rate should not be made.

5) More than one definition of failure should be analysed. These could include: revision, development of severe pain or pain as bad as preoperatively, development of mild pain, and occurrence of radiological signs of loosening. Consensus should be sought on the definitions of failure so that trials from different centres can be compared.

6) Results which show that an implant is worse than others should be published as soon as possible and those which indicate that an implant is as good as currently used implants (with a failure rate of about $1 \%$ per year)

ideally require a ten-year follow-up before publication. Results which prove that an implant is better than currently used implants are extremely difficult to obtain however long the follow-up.

\section{APPENDIX 1 - Survival analyses reviewed.}

Jinnah et al 1986

Knutson, Lindstrand and Lidgren 1986

Thomas, Salvati and Small 1986

Walker et al 1986

Ritter and Campbell 1987

Amstutz et al 1988

Linde, Jensen and Pilgaard 1988

Mackinnon, Young and Baily 1988

McCoy et al 1988

Dorey and Amstutz 1989

Engh and Massin 1989

Ranawat and Hansraj 1989

Ranawat, Padgett and Ohashi 1989

Schurman et al 1989

Buechel and Pappas 1990

Howie et al 1990

Kilgus et al 1990

\section{APPENDIX 2 - The life table.}

For each joint replacement determine the length of follow-up and the outcome. The latter can be success, failure, death or loss to follow-up. Construct a life table (Table I): for each year of follow-up, record the number at the start, the number of failures and the number withdrawn. The last includes those who have died, those who have reached the end of the trial, and those lost to follow-up. Calculate the number at risk during the year as the number of patients at the beginning of the year less half the number of withdrawals. Determine the percentage failure rate for the year from the number at risk and the number of failures, and from this the percentage success rate. Calculate the survival rate for each year by cumulating the success rate for all previous years and the year in question.

\section{APPENDIX 3 - The binomial variance equation.}

For a binomial distribution, with $\mathrm{N}$ the number at risk, $\mathrm{P}$ the probability of survival, and $Q$ the probability of failure:

Variance $=\frac{P Q}{N} \quad$ Therefore the Standard Error $\quad S E=\sqrt{\frac{P Q}{N}}$

These equations are approximate and should not be used unless NQ and NP are both greater than 10 (Armitage and Berry 1987).

APPENDIX 4 - The Peto equation (Peto et al 1977).

If, after a certain length of follow-up, the cumulative survival is $\mathbf{P}$ and the number at risk is $N$ then there must have been at least $N / P$ joints at the beginning of the trial. Assuming that there were $N / P$ at the beginning then the binomial variance formula (Appendix 3) gives:

Variance $=\frac{P Q}{N / P}=\frac{P^{2}(1-P)}{N} \quad$ Therefore $S E=P \sqrt{\frac{1-P}{N}}$

The Peto equation is therefore: Standard Error $=P \sqrt{\frac{1-P}{N}}$

For joint replacements the failure rate is low, thus $N / P \approx N$. As a result the Peto equation is not appreciably different from the binomial variance formula and it is inappropriate to use either if the failure rates are low. The Peto equation should not be used unless $N(1-P)$ is greater 
than 10 (Armitage and Berry 1987). For example, for $\mathrm{N}(1-\mathrm{P})$ to be greater than 10 at least 200 joints would have to be followed up for 10 years if the 10 -year survival rate was $95 \%$.

\section{APPENDIX 5 - The 'effective number at risk'.}

Cutler and Ederer (1958) equated the variance determined by Greenwood's formula with the binomial variance formula to determine the 'effective number at risk' $(M)$ :

Greenwood's formula: $\quad \operatorname{Var}(P)=P^{2} \sum \frac{q_{i}}{p_{i} n_{i}}$
Binomial variance formula: $\quad \operatorname{Var}(P)=\frac{P Q}{M}$

Therefore $\quad \mathbf{P}^{2} \sum \frac{\mathrm{q}_{\mathrm{i}}}{\mathrm{p}_{\mathrm{i}} \mathrm{n}_{\mathrm{i}}}=\frac{\mathrm{PQ}}{\mathrm{M}} \quad$ Therefore $\quad \mathbf{M}=\frac{\mathbf{Q}}{\mathbf{P} \sum \frac{\mathrm{q}_{\mathrm{i}}}{\mathrm{p}_{\mathrm{i}} \mathbf{n}_{\mathrm{i}}}}$

where $p_{i}$ is the probability of survival during an internal $i, q_{i}$ is $1-p_{i}$, and $n_{i}$ is the number at risk during the interval. For $t$ intervals $P$ is the cumulative survival probability and $Q$ is $1-P$.

A more useful 'effective number at risk' can be determined by making two further assumptions. The first is that $p_{i}$ and $q_{i}$ are constant for all $i$ (1). Although the failure rate does not remain constant this is a valid assumption as the 'effective number at risk' is used to determine confidence limits around the calculated survival rate. The second is to assume that the failure rates are very low, and therefore $q$ is very small (2) and $p$ and $P$ are not much less than 1 (3).

$\mathbf{P}=\prod p_{i}$ therefore

$(1-Q)=\prod\left(1-q_{i}\right) \approx\left(1-q_{i}\right)^{t} \approx 1-t q_{i}$ because of $(1)$ and $(2)$.

Therefore $\mathrm{Q} \approx \mathrm{tq}_{\mathrm{i}} \quad(4)$

$$
\mathrm{M} \approx \frac{\mathrm{Q}}{\mathrm{P} \sum \frac{\mathrm{q}_{\mathrm{i}}}{\mathrm{p}_{\mathrm{i}} \mathrm{n}_{\mathrm{i}}}} \approx \frac{\mathrm{Qp_{ \textrm {i } }}}{\mathrm{Pq}_{\mathrm{i}} \sum \frac{1}{\mathrm{n}_{\mathrm{i}}}} \approx \frac{\mathrm{Q}}{\mathrm{q}_{\mathrm{i}} \sum \frac{1}{\mathrm{n}_{\mathrm{i}}}} \approx \frac{\mathrm{tq}_{\mathrm{i}}}{\mathrm{q}_{\mathrm{i}} \sum \frac{1}{\mathrm{n}_{\mathrm{i}}}} \text { because (1), (3), (4). }
$$

Therefore the 'effective number at risk' $\quad M \approx \frac{t}{\sum \frac{1}{n_{i}}}$

In other words the 'effective number at risk' is the reciprocal of the average of the reciprocal of the numbers at risk in the year in question and each preceding year (the harmonic mean).

APPENDIX 6 - Rothman's (1978) method of determining confidence limits.

If the confidence limit is $\mathrm{P}^{*}$ then the binomial variance formula gives:

$$
\operatorname{Var}\left(\mathrm{P}^{*}\right)=\frac{\mathrm{P}^{*}\left(1-\mathrm{P}^{*}\right)}{\mathrm{N}}
$$

If the confidence limit is $\mathrm{Z}$ standard deviations from the survival rate then:

$$
\mathrm{P}^{*}=\mathrm{P} \pm \mathrm{Z} \sqrt{\frac{\mathrm{P}^{*}\left(1-\mathrm{P}^{*}\right)}{\mathrm{N}}}
$$

This quadratic equation can be solved to give confidence limits of

$$
\mathrm{P}^{*}=\frac{\mathrm{NP}}{\left(\mathrm{N}+\mathrm{Z}^{2}\right)}+\frac{\mathrm{Z}^{2}}{2 \mathrm{~N}} \pm \mathrm{Z} \sqrt{\frac{\mathrm{P}(1-\mathrm{P})}{\mathrm{N}}+\frac{\mathrm{Z}^{2}}{4 \mathrm{~N}^{2}}}
$$

This equation can be used to obtain confidence limits with a personal computer. For $95 \%$ confidence limits $Z=1.96$.

The authors would like to thank Professor R. Peto for statistical advice. No benefits in any form have been or will be received from a commercial party related directly or indirectly to the subject of this article.

\section{REFERENCES}

Acurio MT, Friedman RJ. Hip arthroplasty in patients with sickle-cell haemoglobinopathy. J Bone Joint Surg [ Br] 1992; 74-B :367-71.

Amstutz HC, Yao J, Dorey FJ, Nugent JP. Survival analysis of T-28 hip arthroplasty with clinical implications. Orthop Clin North Am $1988 ; 19: 491-503$.

Armitage P, Berry G. Statistical methods in medical research. Second ed. Oxford: Blackwell Scientific, 1987.

Austin MA, Berreyesa S, Elliott JL, et al. Methods for determining long-term survival in a population based study. Am J Epidemiol $1979 ; 110: 747-52$.

Bergman NR, Rand JA. Total knee arthroplasty in osteonecrosis. Clin Orthop $1991 ; 273: 77-82$

Bowman RR, Guyer WD, Bos GD. Total knee arthroplasty at a Veterans Administration Medical Centre. Clin Orthop 1991; 269:51-7.

Buechel FF, Pappas MJ. Long-term survivorship analysis of cruciatesparing versus cruciate-sacrificing knee prostheses using meniscal bearings. Clin Orthop 1990; 260:162-9.

Charnley J. The long-term results of low-friction arthroplasty of the hip performed as a primary intervention. J Bone Joint Surg [Br] 1972; 54-B:61-76.

Cutler SJ, Ederer F. Maximum utilisation of the life table method in analysing survival. J Chron Dis 1958; $8: 699-712$.

Dobbs HS. Survivorship of total hip replacements. J Bone Joint Surg $[\mathrm{Br}] 1980 ; 62-\mathrm{B}: 168-73$

Dorey F, Amstutz HC. The validity of survivorship analysis in total joint arthroplasty. J Bone Joint Surg [ Am] 1989; 71-A :544-8.

Engh CA, Massin P. Cementless total hip arthroplasty using the anatomic medullary locking stem. Clin Orthop 1989; 249:141-58.

Greenwood Mjr. Appendix I. The "errors of sampling" of the survivorship tables. In: $A$ report on the natural duration of cancer. Reports on Public Health and Medical Subjects, No 33. London: His Majesty's Stationary Office, 1926.

Howie DW, Campbell D, MCGee M, Cornish BL. Wagner resurfacing hip arthroplasty: the results of one hundred consecutive arthroplasties after eight to ten years. J Bone Joint Surg [ Am] 1990; 72A :708-14.

Jinnah RH, Amstutz HC, Tooke SM, Dorey F, Dalseth T. The UCLA Charnley experience: a long-term follow-up study using survival analysis. Clin Orthop 1986; 122:164-72.

Kaplan EL, Meier P. Nonparametric estimation from incomplete observations. J Am Stat Assoc 1958; 53:457-81.

Kavolus CH, Ritter MA, Keating EM, Faris PM. Survivorship of cementless total knee arthroplasty without tibial plateau screw fixation. Clin Orthop 1991 ; 273:170-6.

Kilgus DJ, Amstutz HC, Wolgin MA, Dorey FJ. Joint replacement for ankylosed hips. J Bone Joint Surg [ Am] 1990; 72-A :45-54.

Knutson K, Lindstrand A, Lidgren L. Survival of knee arthroplasties: a nation-wide multicentre investigation of 8000 cases. $J$ Bone Joint Surg [ Br] 1986; 68-B:795-803.

Laupacis $A$. The validity of survivorship analysis in total joint arthroplasty. J Bone Joint Surg [ Am] 1989; 71-A :1111-2.

Lettin AWF, Ware HS, Morris RW. Survivorship analysis and confidence intervals : an assessment with reference to the Stanmore total knee replacement. J Bone Joint Surg [Br] 1991 ; 73-B :729-31.

Linde F, Jensen J, Pilgaard S. Charnley arthroplasty in osteoarthritis secondary to congenital dislocation or subluxation of the hip. Clin Orthop 1988; $227: 164-71$.

Llinas A, Sarmiento A, Ebramzadeh E, Gogan WJ, McKellop HA. Total hip replacement after failed hemiarthroplasty or mould arthroplasty: comparison of results with those of primary replacements. $J$ Bone Joint Surg [Br] 1991; 73-B:902-7.

Mackinnon J, Young S, Baily RAJ. The St Georg sledge for unicompartmental replacement of the knee: a prospective study of 115 cases. J Bone Joint Surg [Br] 1988; 70-B :217-23.

Marti RK, Schüller HM, Besselaar PP, Vanfrank Haasnoot EL. Results of revision of hip arthroplasty with cement : a five to fourteen-year follow-up study. J Bone Joint Surg [ Am] 1990; 72-A :346-54.

McCoy TH, Salvati EA, Ranawat CS, Wilson PD Jr. A fifteen-year follow-up study of one hundred Charnley low-friction arthroplasties. Orthop Clin North Am 1988; 19:467-76. 
Merle d'Aubigné R, Postel M. Functional results of hip arthroplasty with acrylic prosthesis. J Bone Joint Surg [Am] 1954; 36-A: 451-75.

Moran CG, Pinder IM, Lees TA, Midwinter MJ. Survivorship analysis of the uncemented porous-coated anatomic knee replacement. J Bone Joint Surg [ Am] 1991 ; 73-A :848-57.

Nelissen RGHH, Brand R, Rozing PM. Survivorship analysis in total condylar knee arthroplasty: a statistical review. J Bone Joint Surg [Am] 1992; 74-A :383-9.

Pearson ES, Hartley HO. Biometrika tables for statisticians. Vol. 1. Cambridge: Cambridge University Press, 1966:227.

Peto J. The calculation and interpretation of survival curves. In: Buyse ME, Staquet MJ, Sylvester RJ, eds. Cancer clinical trials: methods and practice. Oxford, etc: Oxford University Press, 1984:361-80.

Peto R, Pike MC, Armitage P, et al. Design and analysis of randomized clinical trials, requiring prolonged observation of each patient: II, analysis and examples. Br J Cancer $1977 ; 35: 1-39$.

Ranawat CS, Hansraj KK. Effect of posterior cruciate sacrifice on durability of the cement-bone interface: a nine year survivorship study of 100 total condylar knee arthroplasties. Orthop Clin North Am 1989; 20:63-9.

Ranawat CS, Padgett DE, Ohashi Y. Total knee arthroplasty for patients younger than 55 years. Clin Orthop 1989; $248: 27-33$.

Rand JA, Ilstrup DM. Survivorship analysis of total knee arthroplasty: cumulative rates of survival of 9200 total knee arthroplasties. J Bone Joint Surg [ Am] 1991 ; 73-A :397-409.

Ritter MA, Eizember LE, Keating EM, Faris PM. The survival of total knee arthroplasty in patients with osteonecrosis of the medial condyle. Clin Orthop 1991; 267:108-14.

Ritter MA, Keating EM, Faris PM, Brugo G. Metal-backed acetabular cups in total hip arthroplasty. J Bone Joint Surg [Am] 1990; 72A:672-7.

Ritter MA, Campbell ED. Long-term comparison of the Charnley, Muller and Trapezoidal-28 total hip prostheses: a survival analysis. J Arthroplasty 1987; $1: 299-308$.
Rothman KJ. Estimation of confidence limits for the cumulative probability of survival in life table analysis. J Chronic Dis 1978; $31: 557-60$.

Samuelson K, Nelson L. An all-polyethylene cementless tibial component: a five to nine year follow-up study. Clin Orthop 1990; 260: 93-7.

Sarmiento A, Ebramzadeh E, Gogan WJ, McKellop HA. Cup containment and orientation in cemented total hip arthroplasties. $J$ Bone Joint Surg [Br] 1990; 72-B:996-1002.

Schurman DJ, Bloch DA, Segal MR, Tanner CM. Conventional cemented total hip arthroplasty: assessment of clinical factors associated with revision for mechanical failure. Clin Orthop 1989: 240:173-80.

Scott RD, Cobb AG, McQueary FG, Thornhill TS. Unicompartmental knee arthroplasty: eight to twelve year follow-up evaluation with survivorship analysis. Clin Orthop 1991 ; 271 :96-100.

Sedel L, Kerboull L, Christel P, Meunier A, Witvoet J. Alumina-onalumina hip replacement: results and survivorship in young patients. J Bone Joint Surg [ Br] 1990; 72-B:658-63.

Severt R, Wood R, Cracchiolo A, Amstutz HC. Long-term follow-up of cemented total hip arthroplasty in rheumatoid arthritis. Clin Orthop $1991 ; 265: 137-45$.

Sims ACP. Importance of a high tracing rate in long-term medical follow-up studies. Lancet 1973; 2:433-5.

Skeie S, Lende S, Sjoberg EJ, Vollset SE. Survival of the Charnley hip in coxarthrosis: a 10-15 year follow-up of 629 cases. Acta Orthop Scand 1991 ; 62:98-101.

Tew M, Waugh W, Forster IW. Comparing the results of different types of knee replacements: a method proposed and applied. $J$ Bone Joint Surg [Br] 1985; 67-B:775-9.

Thomas BJ, Salvati EA, Small RD. The CAD hip arthroplasty: five- to ten-year follow-up. J Bone Joint Surg [ Am] 1986; 68-A :640-6.

Walker SJ, Sharma P, Parr N, Cavendish ME. The long-term results of the Liverpool Mark II knee prosthesis. J Bone Joint Surg [Br] 1986 ; 1986 ; 68-B :111-6. 